\title{
Top 10 drugs
}

These tables show the top 10 subsidised drugs in 2007-08. The tables do not include private prescriptions.

Table 1

\section{Top 10 drugs by DDD/1000 pop/day *t}

\begin{tabular}{lc}
\hline Drug & PBS/RPBS \\
\hline 1. atorvastatin & 136.215 \\
2. simvastatin & 52.996 \\
3. ramipril & 29.266 \\
4. perindopril & 23.142 \\
5. esomeprazole & 19.445 \\
6. aspirin & 18.155 \\
7. frusemide & 17.877 \\
8. irbesartan & 17.272 \\
9. omeprazole & 16.678 \\
10. salbutamol & 16.624 \\
\hline
\end{tabular}

Table 2

Top 10 drugs by prescription counts ${ }^{\dagger}$

\begin{tabular}{lc}
\hline Drug & PBS/RPBS \\
\hline 1. atorvastatin & 10542015 \\
2. simvastatin & 5773055 \\
3. esomeprazole & 5221504 \\
4. perindopril & 3836043 \\
5. omeprazole & 3702832 \\
6. paracetamol & 3666627 \\
7. atenolol & 3245793 \\
8. pantoprazole & 3150985 \\
9. irbesartan & 3085338 \\
10. metformin hydrochloride & 2961175 \\
\hline
\end{tabular}

Table 3

Top 10 drugs by cost to Government ${ }^{\dagger}$

\begin{tabular}{|c|c|c|c|}
\hline Drug & $\begin{array}{l}\text { Cost to Government } \\
\text { (\$A) }\end{array}$ & $\begin{array}{c}\text { DDD/1000 pop/day * } \\
\text { PBS/RPBS }{ }^{\ddagger}\end{array}$ & $\begin{array}{l}\text { Prescriptions } \\
\text { PBS/RPBS }\end{array}$ \\
\hline 1. atorvastatin & 585491600 & 136.215 & 10542015 \\
\hline 2. simvastatin & 237274763 & 52.996 & 5773055 \\
\hline 3. clopidogrel & 196649817 & 9.776 & 2636907 \\
\hline 4. esomeprazole & 184420078 & 19.445 & 5221504 \\
\hline 5. salmeterol and fluticasone & 160894401 & $-\S$ & 2874427 \\
\hline 6. olanzapine & 158220450 & 3.051 & 864937 \\
\hline 7. omeprazole & 108931730 & 16.678 & 3702832 \\
\hline 8. rosuvastatin & 104846840 & 9.248 & 1674364 \\
\hline 9. venlafaxine & 104082531 & 13.196 & 2644753 \\
\hline 10. tiotropium bromide & 100464420 & 5.662 & 1437217 \\
\hline
\end{tabular}

* The defined daily dose (DDD)/thousand population/day is a more useful measure of drug utilisation than prescription counts. It shows how many people, in every thousand Australians, are taking the standard dose of a drug every day.

+ Based on date of supply

‡ PBS Pharmaceutical Benefits Scheme, RPBS Repatriation Pharmaceutical Benefits Scheme

$\S$ Combination drugs do not have a DDD allocated

Source: Drug Utilisation Sub-Committee (DUSC) Drug Utilisation Database, as at 30 October 2008. (C) Commonwealth of Australia.

\section{Book review}

\section{Therapeutic Guidelines: Toxicology \& Wilderness. Version 1.}

Melbourne: Therapeutic Guidelines Limited; 2008. 311 pages. Price $\$ 39$, students $\$ 30$, plus postage

\section{Edi Albert, Senior Medical Educator and Co-ordinator, Expedition Medicine Program, General Practice Training Tasmania, and} Medical Officer, Polar Medicine Unit, Australian Antarctic Division, and Medical Officer, Department of Emergency Medicine, Hobart Private Hospital, Hobart
Most sections of this book are of an excellent standard while others are inadequate and disappointing. I think this may reflect some uncertainty about the purpose of the book, which to my mind has not had enough thought put into who will use it, why and how.

The bulk of the book covers important topics in toxicology and toxinology. These sections are well prepared and will undoubtedly be very useful for practising clinicians like me, who rarely deal with such cases.

The book starts with an excellent section on resuscitation which underpins most of the other emergency medicine topics. However, given the book includes 'wilderness topics', it would 